\title{
We the people: The importance of employees in the process of building customer experience
}

Received (in revised form): 20th June, 2007

\section{PATRICK HARRIS}

is Founding Director of thoughtengine, a consultancy working in the areas of Brand, Strategy, Creativity and Futures. Previously, he was Director of Creativity for Orange, managing the strategic think-tank for the visionary CEO, Hans Snook. He has also served as a non-executive director in France Telecom UK R\&D. He specialises in assisting organisations to achieve strategic momentum.

Keywords

internal branding; guiding principles; genuineness; transparency; Orange
Patrick Harris thoughtengine Ltd, I Aragon Road, Kingston, Surrey KT2 5QA, UK Tel: + 447973262630 E-mail: patrick@thoughtengine. co.uk

\section{Abstract}

This paper considers the importance of employees in the process of building customer experience. The paper states that internal investment is rewarded with consistent, quality customer exchanges. Emphasis is first placed on the positioning of brand management within an organisation, and its linkage to strategy. Secondly, the tools of identity and guiding principles are introduced. These tools are used to activate staff by inviting their engagement and by asking them to review the brand from a personal perspective. Identity encourages employees to interpret corporate identity and apply it to their unique situation and skill set. Guiding principles serve as a platform to nurture desired behaviours in the organisation. Together, these two tools better prepare staff to respond to customers. Brand values are presented as the currency to measure the worth of exchanges between organisations and their customers. The paper concludes by presenting a case study of the mobile operator, Orange, during the period 1994-2003.

Journal of Brand Management (2007) 15, 102-114. doi:10.1057/palgrave.bm.2550123; published online 9 October 2007

\section{INTRODUCTION}

Branding is about people. People build brands. People buy brands. The relationship, at first glance, is a simple one-build a good brand and others will buy it. At the heart of this relationship, however, is another group of people, that of the employees. It is the employees who enact the attributes of the brand and whose actions ultimately foster customer experience-whether good or bad. Staff actions should reinforce the promises a brand makes to its customers. If wisely conducted, this reinforcement breeds more success in terms of sales, awareness and loyalty. Employees have the formidable task of demonstrating the brand by the actions they take. The adage actions speak louder than words is a truth that holds firm in the process of building successful brands.

Many organisations, however, fall short of representing the brands they espouse. Sometimes, this disconnection is due to uncommon circumstances. These include sudden market shifts that are external to the organisation. Internal changes-like the loss of a key figurehead or an organisational merger - are also examples where a disconnection, between the brand attributes and employee actions, can be present. These examples, and others like them, provide resilience tests for brands. The question is, can effective internal brand management help to overcome 
these difficult periods? Further, can an ongoing internal brand management process help to preserve a healthy relationship between employee actions and customer experiences?

This paper discusses the importance of inward-facing brand management. Emphasis is given to the positioning of brand management and its relationship with organisational strategy. Separately, the tools of Identity and Guiding Principles are presented as a means of serving the employee effort to enact the brand attributes. Finally, a case study involving the mobile telephone company, Orange, is introduced for illustrative review.

\section{AN INWARD PERSPECTIVE}

It was in his seminal paper of 1937 that Ronald Coase prescribed the basic reasoning of a firm. ${ }^{1} \mathrm{He}$ described the importance of building and maintaining relationships as the very essence of a firm

'A firm, therefore, consists of the system of relationships which comes into existence when the direction of resources is dependent on an entrepreneur.'

If consistency of brand experience is sought, this definition suggests the need for a balanced focus of nurturing and serving internal and external relationships. Yet, in many brand management efforts, resources are usually dedicated to constructing an outward image of the brand. Advertising, packaging and sponsorship are traditional examples. It is commonly accepted that internal characteristics are transferred to the external environment via the employees of the organisation. Further, this transferral may be unintended if left unchecked. This point implies a need to manage, or at least positively influence, the identity that is transferred outwardly-in order to maintain consistency and overall control. Thus, the internal workings of a firm should form an integral part of brand management. Brands today must represent a company's history, future vision and its outward appearance-as well as the internal representation of the organisation. Why, then, do organisations give little attention to internal brand management?

\section{The right level}

Inward-facing brand management must be considered at the appropriate level if it is to succeed. Brand management, when considered as a periphery exercise of a marketing subset is destined to perform poorly. Brand today is a key element of every transaction the organisation engages in and as such should be strategically incorporated into internal activities. Brands do far more than label products or companies. Brands today can

- change market dynamics;

- span across entire markets and enter new markets and

- heavily influence industry business models.

Google, Amazon and Napster are examples of brands that have significantly changed the dynamics of entire markets. Virgin, Marlboro and Caterpillar are good illustrations of brands that can span industries or enter new industries. Finally, MySpace and Blackberry are brands of influence that have stimulated enormous changes to business models in their respective markets.

Despite this shift in the influence of brands, intelligent dialogue between brand managers and the strategic elements of the firm is often lacking. In reality, management of the brand must feature in all that 
the company undertakes, internally and externally. Brand must be prevalent in strategy, training, objective-setting, working style, facilities and much more. Ind (2004), when discussing the concept of living the brand, argues that brands come to life when internal and external boundaries are blurred. ${ }^{2}$ Most importantly, brand management must also be well integrated into the activities of the organisation if it is to deliver quality customer experiences.

But the phrase living the brand does not necessarily express the integration of brand at a strategic level of the organisation. Organisations that unite strategy and brand possess cohesive workforces that demonstrate sound direction, incorporate a recognisable approach and present a high-quality, consistent customer experience. Ind's phrase can be extended for organisations that provide a strategic and integrated focus of brand managementbeing the strategy and living the brand.

\section{What they do, not what they say}

Internal branding should concentrate more on context rather than content. It should focus on why an activity occurs more than the brand compliance of the activity itself.

A hypothetical example of branding the company canteen is helpful as an illustration. In this circumstance, it is not the branded colour of the crockery or the ability to reinforce company messages on the walls that is critical. Rather, emphasis should be on the behaviours exhibited when serving or receiving food, and on the atmosphere that is conveyed by staff. Behaviours are visible evidence of the brand's capacity to influence. Too often, it is the focus on tangible items that receive the bulk of the attention-ensuring that the content meets stringent brand guidelines-while overlooking the con- textual settings and behaviours of the people involved.

The relationship between employees and customers is-or at least should begenuine, two-way and sincere. What is displayed externally is chiefly a reflection of the activities of the internal organisation. For this reason, inward brand management should not be limited to providing training material for customerfacing staff only. Instead, it should be the creed by which the whole organisation elects to live and breathe. Internal activities should always underpin the customer experience sought. Thus, brand management efforts must be focused inside the organisation as much as, and possibly more than, they are externally. The key is to provide staff with appropriate tools, allowing them to be the strategy and live the brand.

\section{IDENTITY: BUILDING UNDERSTANDING}

Corporate identity, the persona of an organisation, is widely used by companies and agencies alike. It is normally expressed in a hierarchical set of descriptive termsfrom say, vision to values - and provides guidelines for how the organisation expresses itself. Corporate identity is a valuable asset of any brand manager's toolkit.

Corporate identity is not necessarily the best tool for employees, however. A workforce is, after all, a collection of people and often, a corporate identity does not adequately speak to each as an individual. Further, individuals see organisational change and shifts in corporate identity as uncomfortable and difficult to accept. Employees take these shifts personally and feel lost when another directive arrives, with a new focus, and the CEO asks for their buy-in-once again. 


\section{Activate, not automate}

Inside organisations, it is not buy-in that is necessary, but momentum. Buy-in is a flawed concept that suggests 100 per cent effectiveness in the communication of an idea, 100 per cent belief in it by the listener and 100 per cent efficiency in enacting it. Momentum, however, is created by communicating the gist of an idea and afterwards, encouraging individuals to interpret it, apply it to their unique situation and then use their individual skills to address it. Momentum taps into the collective wisdom of the staff and invites their participation. Here identity is still in use, but it is not an induced corporate identity communicated from the upper echelons of the company. Instead, individual identity is developed by regularly encouraging employees to interact with the company position. This allows them to reach a greater appreciation of its meaning to them personally, or as smaller teams of people. This is how it should be. Identity, used as a tool, allows individuals to increase their overall understanding of the organisation and to personally ingest its meaning. Workshops, training programmes and promotion of good dialogue are good methods to achieve this aim.

There are several benefits of the process of engendering identity. Firstly, employees have a stronger personal sense of organisational purpose. They know what to do and why they should do it. Secondly, they are less affected by significant organisational changes that (inevitably) will occur. They take these changes less personally. Thirdly, they are better equipped to see how their role can make a difference to the company as a whole. Fourthly, a company-wide spirit of involvement and responsibility is in action. Overall, their understanding is more consistent through change and this consistency features readily in their work. They can, in effect, be the strategy.

The next step is to help staff to underpin their understanding with appropriate behaviours.

\section{GUIDING PRINCIPLES: NURTURING DESIRED BEHAVIOUR}

Consistent behaviour cannot be prescribed, nor can cultures be assigned. Cultures are more amorphous than this. Consistent behaviour can be nurtured, however. By nurturing a few desired behaviours, a sought-after organisational culture is more likely to develop. This focus is served well by the concept of Guiding principles.

Guiding principles are not rules, because rules are typically prescriptive and describe what can and cannot be done. They are not objectives, either, as guiding principles are interpretable. They possess a high degree of flexibility, while objectives should always adhere to the SMART rule of thumb. ${ }^{3}$ Finally, guiding principles are not habits, as habits are traditionally, outof-date or unchecked actions that are routinely applied. Instead, guiding principles are a small collection of memorable expressions of behaviour-about three to six in total. They describe behaviour that must be present in order to fulfil strategic and brand aims. Interestingly, guiding principles are useful regardless of the changes in circumstances. Thus, even in times of instability, guiding principles represent the inherent behaviour that individuals can turn to and depend on. Together, they underpin an organisational identity and are necessary to nurture a desired culture. A good example is the following

'Everything in moderation, nothing in excess.'

This phrase when applied across a number of individuals can have different 
interpretations. To some, the phrase indicates the need for a steady, even approach. To others, it might mean that an extreme intake or exposure is acceptable-on occasion, but not regularly. In all cases, individuals will be able to respond in a manner that is in keeping with the desired behaviour, but that suits their situation. Consider too the guiding principle of face to face. To customer-facing staff, its meaning might be very clear - be with the customer whenever possible. To backroom staff, however, it might have usefulness in terms of how they treat email or how feedback is provided to colleagues.

The power of guiding principles is that they can be communicated in a straightforward manner, and yet their meaning is always personal to each individual and open to interpretation. The combination of identity and guiding principles is a mobilising force for organisations. Together, they help to form employee behaviour and to channel employee actions and decisions in desired directions. As a result, the organisation becomes more adaptable in terms of the changes it faces, and yet will be consistent in its response. Meanwhile, employees are made more aware of the aims of the organisation and are actively engaged in delivering its success. They are able to live the brand.

\section{A cautionary tale}

Guiding principles, together with identity, should hold meaning for the individuals who use them. This is best achieved by allowing a significant cross-section of the organisation to develop them. It is not always possible that one set of guiding principles will serve the whole organisation and some limited regional or team variation should be encouraged. The process should be highly integrated and inclusive. However, the commitment to involve staff must be genuine and purposeful. It must be supported by the presence and involvement of senior managers. Employees do notice when they are being served a placebo process. Less than genuine attempts to involve staff can result in far fewer committed people than desired-perhaps even an employee revolt. Having a few members of staff involved is a far cry from having an entire workforce mobilised and committed to the cause. Martina Navratilova expressed it fittingly when she described the dedication required to achieve sporting excellence- 'It's like ham and eggs. The chicken is involved, the pig is committed.'

\section{WHERE IS THE CUSTOMER?}

Thus far, this paper has concentrated most of the discussion on the organisation itself-not the customer. This is deliberate because it

- illustrates the yawning gap in internal focus;

- establishes an appropriate sequence of events required and

- demonstrates the amount of effort that is necessary in order to deliver desired customer experience.

This in-depth focus on internal matters provides two key brand management deliverables. Firstly, it builds a robust foundation for stimulating desired internal attitudes. These, in turn, become products and services that deliver a valued customer experience. Secondly, undertaking exercises of understanding and behaviour ensures that downstream activities become easier to address and are implemented with greater consistency.

As the mantra suggests, the customer is always right. An inward-facing brand 
process, however, better prepares the organisation to respond to customers in the right way.

\section{GENUINENESS AND TRANSPARENCY-READY TO FACE THE WORLD}

In today's marketplace, it is important that any presentation made to a customer needs to be wholly genuine. Further, the organisation that delivers the product or service needs to be transparent. This need for genuineness and transparency does not stem from brand management manuals. Rather, this is a necessary organisational response to today's consumers, who are armed with choices, control and the tribal nature of communities.

\section{Choices, control and community}

In recent times, consumers have gained access to new and powerful tools. In the main, these consumer tools refer to new communication technologies such as the internet, mobile telephony and peerto-peer connectivity. Less hyped, enabling technologies such as increasing digital storage capacities (ie the ability to access, store and transfer large volumes of information) are also critical consumer tools. While each of these technologies no longer represents stirring news on their own, none of them should be underestimated in terms of the lasting social change that they are introducing. They have the capacity to leapfrog technology generations, connect previously isolated areas, enable the connected portion of the planet to communicate and they provide access to an ever-increasing sea of information.

In brand management terms, these tools have created a state of caveat venditor, where markets provide near limitless choices and the consumer is able to control the exchange. If the company cannot respond, a raft of alternatives is just a mouse click away. Of particular concern for brand mangers is that traditional systems of trust and relationship building are changing at alarming rates. The current generation is the first to be exposed to an endless landscape of sources of trust and the ability to bypass middlemen. As recent as the late $1980 \mathrm{~s}$, for example, there were only a few widely acceptable sources of news. Now, news is available from numerous providers, aggregators and commentators-whether in the form of traditional institutions, blogs or others. Indeed, many consumers of news have also become commentators and publishers in their own right.

\section{A gathering storm}

In strategic and brand terms, this means that segments of customers can band together-practically overnight—and shift organisational decisions in a way that has never been possible before. A few activists can cause years of unwelcome press and lasting grief with court cases against organisations like McDonalds. ${ }^{4}$ Brand reputations can suffer from reported employment practices in manufacturing assembly plants. ${ }^{5}$ During the construction of this paper, vegetarians united to protest a decision by Masterfoods-makers of Mars and Twix chocolate bars-to use animal rennet in some of its products. The result? Masterfoods publicly admitted that it had made a mistake and reversed the decision. ${ }^{6}$ It is now reported that they are reviewing the broader product range with the diets of vegetarians in mind. ${ }^{7}$

Finally, an illustration involving Apple's customer base shows the variety of involvement by informal customer tribes over time. From its inception, Apple has 
attracted an enormously loyal customer base. ${ }^{8,9}$ This was true even during Apple's lethargic progress in the 1980s. In those dark days, lore has it that some near-fanatical customers even loitered in computer stores to promote Apple products to wouldbe buyers. Surely this was a welcome if not unexpected asset for Apple at the time. In recent times, however, that same loyal base has applied pressure to Apple itself - with expert leadership from Greenpeace-to improve Apple's eco-friendly practices. ${ }^{10}$ The success of this orchestrated campaign makes the clear point that no brand can ignore the mobilised wishes of its customer base, particularly, a famously loyal one.

The need for transparency and genuineness is not a marketing tool or a branding fad. It is not a management theory for organisational development. It is an irreversible fact of business life that every organisation must learn to address. This need will only increase as consumer tools improve and as more people have access to them.

Brands can no longer state unrealistic statements of aspiration. The truth is that they never should have done so. Now brands, or at least those that aspire to build valued customer experiences, can only state what the organisation can realistically live up to. This requires learning for some, as it is not necessarily the marketing mix that brand managers learned from the era of Madison Avenue thinking.

\section{VALUES-THE CUSTOMER CONNECTION}

Brand values are one of the more familiar terms used by businesses and brand managers. Brand values are also familiar for many customers. This is justifiable, as values are tangible brand management tools to be shared with customers.
Organisations should openly state their values and ensure that they are represented in their activities. Simultaneously, customers are able to use the values as benchmarks to evaluate the success of their exchanges with the organisation.

Brand values are more resident in the customer domain than identity and guiding principles, discussed previously. Identity and guiding principles are the strategy in flexible form, and help the employees to be the strategy and live the brand. In contrast, brand values are the currency of customer experiences. Each experience can be considered as positive or negative, in a brand sense. Where the brand values are present in a customer exchange and supported by the actions of staff encountered, the transaction can be considered a positive one. In these positive exchanges, the brand is reinforced and the relationship deepens as a result. In contrast, negative transactions occur when the brand values are not evident in the transaction. Here, the customer completes a transaction (or aborts it) but has a less clear understanding of the brand and its position.

Brand-based organisations would do well to treat these measures of brand values as importantly as they do other measures of success. This is because the degree to which brand values are communicated is directly related to how much the consumers buy into the actions of the company and its longer-term perspective.

\section{PUTTING IT ALL TOGETHER- A CASE STUDY}

The mobile telephone company, Orange, provides an excellent case study for review. Orange was a fast-growing, brand-based and industry-influencing organisation, particularly in the mercurial heyday of 1994-2003. It was the last of four players 
to launch in the crowded UK market and was heavily dependent on a differentiated position. From this unlikely position, Orange proceeded to excel at providing excellent customer experiences. ${ }^{11}$

Like many organisations, however, Orange also faced a number of operational issues, internally and externally. Some examples included-dealing with interdepartmental rivalries, supplier inconsistencies, overcoming the communication needs of a large employee base and management and staff mismatches at various levels. Again, these are common issues that many organisations face. Orange, however, was able to regularly overcome these issues, or at least manage them, by demonstrating its strong sense of organisational purpose and by encouraging employee engagement with the brand. The brand values were thoroughly incorporated into the entire organisationproduct development meetings, personal development, employee achievement citations and much more.

During the period mentioned above, a strong sense of understanding and awareness existed in the organisation. It would not have been out of place for a highly technical meeting on telecommunications platforms and infrastructure to close with a discussion on how to make the chosen concept look and feel Orange. Further, the senior team, and in particular the CEO, regularly and personally conducted visible deeds that reinforced the values. These deeds were visible to the organisation and were passionately recounted, until they became symbols of the organisational identity. They developed into rich seams of company lore that were ardently repeated.

Below are two examples from the period that illustrate

- one employee's personal interpretation and application of brand values and
- how senior management deeds can build lasting, purposeful narrative.

\section{Doohickey Day}

Many technology companies face a challenge in getting the marketing team to understand the technology team and vice versa. Communications between the two groups can become sterile, even where best intentions are present, normally due to a lack of understanding between the two groups. Orange was no exception. A unique solution for Orange was developed, however, by one of its engineers. He created a forum for sharing technical developments in an engaging format, which the marketing team would appreciate. The concept was called Doohickey Day, named for the way that engineers in the Dilbert cartoon strip sometimes convey key technologies to their colleagues.

The forum consisted of engineers who would present innovative and upcoming technological concepts to a crowd of (largely) marketing people. The attendees all sat at round tables, each with a large red button in the centre. Each button played a unique sound when pressed. When speaking, the technology presenters were not allowed to use acronyms or jargon to describe the concept. If this did occur, the attendees could 'buzz' the speaker by pressing the red button. At the end of the day, the speaker who had the most buzzes against him was given a penance. The penance? They were made to work in the marketing department for a day!

This process tackled an age-old issue of inter-department communication, but did so in a way that was engaging. In fact, the whole exercise was straightforward, refreshing, dynamic, honest and friendlyreinforcing the five espoused Orange 
values. ${ }^{12}$ Most importantly, the concept was created out of an employee's personal understanding of how the brand values could be applied to solve an internal issue. It is just one of the many ways that an internal brand management focus helped to significantly influence the workings of the organisation and ultimately, the services that were developed for customers.

\section{Customers missing in the boardroom}

A second example focuses on just one visible senior management deed that carried particular resonance throughout the organisation. It involved two members of the Corporate Strategy team, who were tasked with presenting a concept to the Executive Board. While presenting the early portion of a PowerPoint presentation, the CEO, Hans Snook, thanked the two strategy representatives for their effort and asked them to leave. The presenters quickly pointed out that they were not finished and that they still had more pages to discuss. Mr Snook replied that given that they had already presented a number of pages and that they had not yet mentioned the customer, they were indeed, finished. The embarrassed presenters duly left the now silent boardroom.

The impact of this brief episode was immediate and far-reaching. First, it concentrated the minds of the strategy team for that particular presentation and for every subsequent piece of work undertaken. Secondly, the board members too took away additional insight that day into how the CEO was absolutely determined to represent the customer at all costs. ${ }^{13}$ Finally, stories about that day meandered throughout the organisation, establishing a firm body of lore about the importance of remembering the customer and it served as a constant reminder to the whole of the company.

\section{Talent spotting}

Readers might see these two examples and look for the role of the brand manager in both, for neither example is a result of a brand-led, marketing initiative. One example cited the insight of a single employee and the other referenced the strong personality of the CEO. Nevertheless, the role of brand managers is still key in both. The stories show the underlying need for brand managers to recognise when brand values are being enacted and to support and endorse these activities. Eventually, support from brand managers with regard to Doohickey Day helped it to grow from a small gathering of people to a highly engaging exchange for hundreds of attendees. Separately, brand managers religiously built the CEO's insistence of putting the customer first in every communication exercise.

Brand management in these instances did not translate into the clever invention and leadership of a specific project. Actually, it required the wisdom to locate good values-based examples when they occurred and the dedication to support them thereafter.

\section{Benefit for the customer}

The Orange example is also beneficial for seeing how the brand values were reiterated externally, in customer exchanges.

From the outset, Orange presented an interesting proposition that people wanted to be a part of. At launch, in 1994 for instance, no product-specific materials were used. Instead, a broad brand awareness campaign was built, in an industry that was woefully lacking in powerful consumer brands. It hinged on the phrase 
the future's bright, the future's Orange, a phrase that is still immensely popular today and that is politely modified with wordplay in media coverage. Below are some examples of how Orange reinforced the five brand values, particularly in circumstances of customer experience.

\section{Friendly and straightforward}

The values of friendly and straightforward were in widespread use at all Orange touchpoints. Innovative solutions at that time are now readily recognised as industry standards. These included uncluttered shop environments, a reduced number of simplified talk plans and the absence of technology in all advertising. Customers readily bought into a lifestyle concept instead of making independent, productbased, purchasing decisions. Presentation material relied on brief, but clear phraseology and powerful, supportive images. This approach was in complete contrast to an industry that was technologically oriented and rife with complex explanations. Philosophically, the friendly perspective was internally viewed as a child leading an adult into a safe and rewarding future. Thus, advertising often used children's concepts such as bicycles and kites, or simple line drawings to explain services.

But even the name Orange, while highly respected today, was seen as innovative and unusual. Practically every operator name at that time featured some aspect of mobile telephony-words like phone, net or cell-and thus emphasised technology. A few company names existed outside the technology sphere, but the companies failed to market themselves in a nontechnological way. Today, this use of a company name to distance the organisation from mobile technology is in widespread use-Wind, Blue, $\mathrm{O}^{2}, 3$ are some specific examples-but the process began with Orange.

\section{Honest and dynamic}

These values were reiterated in several specific and unique offerings for the industry. Per-second billing and caller identification represented the initial manifestations of honesty and dynamism. Until the arrival of Orange, mobile users paid for minutes or portions of minutes even when using the mobile to make a call of only seconds. The concept of caller identification was unthinkable. Now, persecond billing and caller identification are worldwide industry standards. Other industry-leading examples included the Orange Value Promise, which gave customers the chance to use other operator tariffs on the Orange network if desired and the Orange Network Promise, where credit was given to users who experienced network connectivity issues.

Orange also influenced the analyst community. Prior to the arrival of Orange, operators were fixated with average revenue per user (ARPU). While ARPU was, and still is, a critical measure, Orange was nevertheless able to introduce the concept of Customer Lifetime Subscriber Value (CLSV). This was a measure of APRU and customer churn, which expressed value over the lifetime of a customer relationship. The analysts of the industry lauded it, as it suited the longterm payback nature of mobile network investment.

Most importantly, honesty was evident in customer relationships. For example, telephone-based customer service staff would willingly indicate to customers when it was felt that they were paying too much by subscribing to the wrong tariff. Customers, pleasantly surprised, would happily migrate to the lower-priced tariff, 
but thereafter feel inclined to stay with the network longer, underpinning the CLSV perspective above. This is an example of how an extensive internal focus on being the strategy and living the brand ensured that the customer expectations were not just met, but very often exceeded at each exchange.

\section{Refreshing}

Collectively, the Orange position represented a refreshing perspective for the industry. Technology was relegated, customer needs were emphasised and communications were clear, but concise. Moreover, the organisation expressed an ability to see beyond its services and even developed the ability to laugh at itself. A good example of this phase was in a run of print advertising that listed activities that could be accomplished with the mobile switched on or switched off. Separately, cinema advertisements of the fictional Orange Film Board reinforced a refreshing perspective. Here, the 'board' cheekily pitched bogus film scripts with the mobile phone as the star, before stating the core message of Don't let a mobile phone ruin your movie.

\section{FINAL CAUTION-BE CAREFUL WHAT YOU WISH FOR}

Striving for excellent customer experiences is what Orange sought and is what most organisations seek. It is difficult to achieve and maintain excellence, as this paper has indicated. Worryingly, however, there are some additional, and perhaps unexpected, pitfalls for successful brands.

Great brands attract talent. People want to be associated with them. They sense the opportunity to display their abilities. Over time, however, great brands attract idlers too. Idlers are those people who are good at doing very little, surviving instead on the efforts of the people around them. For them, there is less to do in a successful company. They can be more difficult to locate, and they share in a larger reward than if they worked in a lesser organisation.

Great brands can also suffer from too much of a good thing. Messages that are constantly stated, but are poorly reinforced by actions, can lead to traits of arrogance or complacency in the organisation. Soon, the once valuable programme of community building is perceived as nothing more than corporate propaganda. Sadly, an unending diet of statements, without positive reinforcement, can bring about a culture that is at odds with the brand position that is being espoused.

Finally, great brands can be poor at knowing when the period of success is over. No organisation is excellent forever. In fact, the life expectancy of organisations is quite low, according to Arie de Gues. ${ }^{14}$ While at Shell as Head of Planning, he searched for benchmarks from other organisations that were, like Shell, at least 100 years old. Interestingly, he and his team found only 40 firms of that age. They concluded that organisations could indeed last longer, but that many of today's company systems do not nurture this kind of tenure. The result of shorter-term systems is that most organisations will eventually face fundamental change. This could be in their marketplace, political system or in the loss of a leader. Each of these examples indicates a need to reevaluate the emphasis in strategy and brand management. The issue here is that while poor and average organisations live in a very real world of knowing that the end could occur at any time, successful organisations are often blind to anything other than business-as-usual expectations. 


\section{CONCLUSION}

This paper has discussed brand management and the customer experience. This has been done not by dissecting brand management into its specific components, but by illustrating the robustness of brand management when placed appropriately in an organisation. The paper has also highlighted the need to supply employees with tools-identity and guiding principles- to interpret and personally apply organisational attributes. Among other benefits, these employee tools help to breed a consistent and high-quality customer experience externally. Both customers and organisations can determine the overall worth of individual customer exchanges by the presence of brand values.

Finally, it is worth reiterating that people are the key ingredient in any branding effort. It is the actions of people inside an organisation that feed the experience of those outside the company. The journey of providing quality customer experience is long and can be arduous. It begins at the heart of an organisation. It begins with employees who are being the strategy and living the brand.

\section{References and Notes}

(1) Williamson, O. E. and Winter, S. G. (1993) 'The Nature of the Firm: Origins, Evolutions and Development', Oxford University Press, New York.

(2) Ind, N. (2004) 'Living the Brand', 2nd edn, Kogan Page, London.

(3) SMART-A popular mnemonic to recall best practice for constructing objectives. It states that objectives should always be Strategic, Measurable, Achievable, Realistic and Time-based.

(4) McDonalds Restaurants versus Morris \& Steel, colloquially known as the McLibel Case-which, despite the label, McDonalds successfully argued.

(5) Consider the accusations placed on corporations by corporate critics such as Naomi Kline (No Logo) and Michael Moore (Roger and Me, Fahrenheit 911, Bowling for Columbine).
Consider too the resulting difficulties that can occur when trying to defend against same (eg establishing the difference between political speech and corporate speech in Kasky $v$ Nike).

(6) See http://www.masterfoodsconsumercare.co.uk/ veg_status.asp (reprinted) 'At Mars UK we recently changed the source of some of the whey which is used in some of our chocolate products. We have received lots of feedback that this decision has made it difficult for some of you, especially those of you who are vegetarians, to continue to enjoy our products. We made a mistake. We apologise. The consumer is our boss. Therefore we listen to you and your feedback. As a company we value openness, honesty and diversity and we believe that anybody should be able to choose freely from our range of chocolate brands. But being sorry isn't enough. Therefore we commit to you today, that we at Mars UK will ensure that a selection of your favourite brands-Mars bars, Snickers bars, Galaxy and Maltesers, will be suitable for vegetarians in the near future. To this effect we are starting to change our manufacturing process today. We will keep you informed of our progress against this commitment through regular updates on this website. Please accept our apology and keep talking to us'.

(7) See http://www.vegsoc.org/news/2007/mars. html (reprinted) 21st May, 2007. 'The Vegetarian Society's door is always open to companies seeking to better serve vegetarians. A Masterfoods representative has made contact with us and we are very pleased that they now recognise the importance of integrity to all their customers, especially vegetarians. We cannot endorse any planned actions by the company until we receive detailed assurances about the ingredients and processes involved in production but we are delighted that Mars UK has been honest enough to mark the beginning of National Vegetarian Week by admitting that it made a mistake. The best thing they could do now is, of course, to take up our accreditation scheme and earn the right to brand their products as Vegetarian Society Approved. Dr Annette Pinner, Chief Executive, The Vegetarian Society.

(8) Kahney, L. (2002) 'Mac loyalists: Don't tread on us', Wired, 2nd December, 2002.

(9) Captain, S. (2006) 'Fans storm Apple's 5th Avenue Store', Wired, 19th May, 2006.

(10) The successful and award-winning Green my Apple web-based campaign organised by Greenpeace is now archived. This weblink tells the story of how Greenpeace enticed the Apple customer base to influence the organisation's green policy, http://www.greenpeace.org/ international/news/greening-of-apple-310507. 
(11) Orange gained the top ranking for customer satisfaction among mobile phone contract customers in the annual J.D.Power and Associates 2005 UK Mobile Telephone Customers Satisfaction Study, seven times in the period 1998-2005. In October 2005, Orange won the Mobile Choice Consumer Awards - voted for by readers of Mobile Choice magazine-for Best Network Operator for the fifth consecutive year. In the same month, Orange also won Best International Mobile Operator at the World Communications Awards.

(12) Today, the Orange.com website cites these five behavioural values alongside three additional values that describe the reputation it seekstrusted, innovative and responsible.

(13) A brief synopsis on Hans Snook, his business philosophy and his time at Orange is in the book 'Digerati Glitterati: High-tech Heroes' by Christopher Langdon and David Manners (2001), John Wiley \& Sons.

(14) Arie de Gues worked for Royal Dutch Shell for nearly 40 years. His book, The Living Company (Nicholas Brealey Publishing), introduces the concept of treating companies like living work communities. It is regularly shortlisted as one of the best management books of all time. 